\title{
A GESTÃO DE CONFLITOS URBANOS E O DIREITO À CIDADE COMO LIMITE À GENTRIFICAÇÃO
}

\author{
Gabriel de Oliveira Silva ${ }^{1}$ \\ Juliana Bruschi Martins ${ }^{2}$ \\ Aline Ouriques Freire Fernandes ${ }^{3}$
}

\section{RESUMO}

Com o crescimento urbano desordenado no Brasil, surgem conflitos habitacionais causados pelo fenômeno social da gentrificação. Neste contexto, o presente trabalho tem como objetivo principal identificar a relação entre o direito à cidade e a gentrificação. Foi utilizada a seguinte metodologia: pesquisa teórica, qualitativa, com objetivo exploratório, seguindo diretrizes do método dialético, e executadas através dos procedimentos de revisão de literatura e pesquisa documental. Por fim, o artigo conclui pela possibilidade de utilização de instrumentos jurídicos com base no direito à cidade como limite à gentrificação urbana, garantindo segurança possessória ou de propriedade às classes mais baixas no contexto urbano.

PALAVRAS-CHAVE: Direito à cidade; gentrificação; limite; democratização; gestão de conflitos

\section{URBAN CONFLIT MANAGEMENT AND THE RIGHT TO THE CITY AS A LIMIT TO GENTRIFICATION}

\begin{abstract}
With the disorderly Brazilian urban growth, housing conflicts arise due to the social phenomenon of gentrification. In this context, the present work has as main objective to identify the relation between the right to the city and gentrification. The following methodology was used: theoretical and qualitative research, with an exploratory objective, guidelines of the dialectical method, and performed through the procedures of literature review and documentary research. The article concludes by the possibility of using legal

\footnotetext{
${ }^{1}$ Mestrando em Direito e Gestão de Conflitos pela Universidade de Araraquara (UNIARA). Advogado em São Paulo. Assessor do Defensor Público-Chefe da Defensoria Pública da União em São Paulo. Membro do Conselho-Geral do Instituto de Promoção e Proteção de Direitos Humanos. Endereço eletrônico gabrileoliverasilv@gmail.com. Orcid iD https://orcid.org/0000-0002-6843-4134. Endereço postal: Rua Samuel Brasil Bueno, no 1607, BI. 28, apto. 203, CEP 14801-013, Araraquara/SP.

${ }^{2}$ Advogada da Interligação Elétrica do Madeira S.A, formada pela Universidade Estadual Paulista ("UNESP"), com MBA em Direito Empresarial e Gestão Empresarial, ambos pela Fundação Getúlio Vargas ("FGV"). Mestranda em Direito pela Universidade de Araraquara ("UNIARA"), área de pesquisa Gestão de Conflitos. Endereço eletrônico: julianabruschi@hotmail.com. Orcid iD https://orcid.org/0000-0003-4284-9662. Endereço postal Av. Gumercindo Siqueira, 1130, apt 261 - Jd. Magonólias - Araraquara/SP - CEP 14.802-790.

${ }^{3}$ Doutora em Função Social do Direito e Acesso à Justiça nas Constituições pela FADISP - Faculdade Autônoma de Direito - São Paulo. Mestra em Direitos Coletivos, Cidadania e Função Social pela UNAERP, especialista em Direito Público e Direito Tributário. Professora titular do Mestrado Profissional em Direito e Gestão de Conflitos e da graduação em Direito da UNIARA-Universidade de Araraquara. Pesquisadora pela FUNADESP. Advogada; E-mail: aoffernandes@uniara.edu.br. Orcid n. https://orcid.org/0000-0001-6584-0471. Endereço postal: Rua Horácio Serafim,111, Cond. Portal das Araucárias, CEP:14805218, Araraquara-SP.
} 
instruments based on the right to the city as limit to urban gentrification, guaranteeing possessory security to the lower classes in the urban context.

KEYWORDS: Right to the city; gentrification; limit; democratization; conflict management.

\section{INTRODUÇÃO}

O crescimento urbano no Brasil se deu de forma desordenada e não planejada. O êxodo de trabalhadores aos grandes centros urbanos criou núcleos de pessoas de baixa renda nas cidades mais populosas do país. Com as melhorias em serviços públicos e comércios em regiões urbanas e a revitalização de centros históricos, classes média e alta começaram a se deslocar às regiões urbanas causando diversos conflitos sociais, entre eles, o fenômeno da gentrificação, ou seja, a expulsão compulsória e não explícita das classes menos favorecidas às regiões periféricas da cidade.

Em contrapartida, novos direitos humanos surgiram nas últimas décadas, ampliando o rol daqueles direitos considerados como mínimos para a garantia de uma vida com dignidade. Essa abertura também impulsionou novas interpretações de direitos já existentes. É nesse contexto que surgem discussões sobre a possibilidade ou não do reconhecimento do direito à cidade como direito humano fundamental.

Em que pese a expressa previsão do direito à moradia em diversos tratados internacionais de direitos humanos, a concepção de direito à cidade vai além da ideia tradicional de habitação, reconhecendo núcleos sociais urbanos como verdadeiros espaços de exercício da democracia. Partindo de tais conceitos, a pesquisa visa encontrar respostas ao problema da gentrificação e a existência de limites jurídicos em tal fenômeno social. Neste contexto, o presente trabalho questiona, por um lado, os limites e as potencialidades da gentrificação para promoção da democracia, ato inerente ao direito à cidade, e, por outro, questiona também, os gatilhos decorrentes da gentrificação para a promoção de conflitos urbanos. Alinhados a tais questionamentos, o objetivo principal deste artigo foi identificar a relação entre o direito à cidade e a gentrificação. Em específico se objetivou: a) identificar os limites inerentes ao exercício do direito à cidade frente a gentrificação; b) analisar o movimento jurídico de normatização do direito à cidade no contexto de gentrificação; c) identificar conflitos decorrentes do fenômeno da gentrificação. A condução dos procedimentos necessários para a realização dos objetivos definidos no parágrafo anterior, foi concebido um mapa metodológico explicitado nas seguintes configurações: pesquisa teórico, 
qualitativa, com objetivo exploratório, seguindo diretrizes do método dialético, e executadas através dos procedimentos técnicos da pesquisa de revisão de literatura e da pesquisa documental, tal qual detalhado na seção seguinte. Já os resultados serão apresentados em outras três seções que se complementam e proporcionam uma visão global da realidade estudada. Em um primeiro momento é conceituado e delimitado o direito à cidade, distinguindo-o do direito à moradia e analisando sua (in)existência no ordenamento jurídico brasileiro, verificando sua previsão na legislação ordinária, Constituição Federal e tratados internacionais de direitos humanos. Após, passa-se ao estudo da gentrificação como fenômeno social. São estudadas sua história, suas causas e suas formas de manifestação no ambiente urbano. Ainda, é verificado se a gentrificação pode ser entendida como forma de violação de direitos humanos fundamentais, especialmente do direito à cidade. Por fim, o artigo analisa quais os instrumentos jurídicos podem ser utilizados para garantir o direito à cidade e, como consequência, impor limite mínimo à gentrificação, garantindo segurança possessória ou de propriedade às classes mais baixas no contexto urbano.

\section{METODOLOGIA E PROCEDIMENTOS DA PESQUISA}

Como indicado anteriormente, para viabilizar a materialização dos objetivos supracitados, a pesquisa foi produzida tendo como norte, a delimitação conceitual da pesquisa teórica, que vista estabelecer o exame rigoroso da natureza, do alcance e das interpretações possíveis do fenômeno estudado (MAZZAROBA; MONTEIRO, 2009), no caso a gentrificação e os limites impostos pelo "direito à cidade", as quais são imbuídas por normativas e legislações específicas, além de ensinamentos doutrinários, os quais foram reinterpretado.

Mazzaroba e Monteiro (2009) pontuam que este tipo de pesquisa tem objetivo de desenvolver, esclarecer e modificar conceitos e ideias, tendo em vista a formulação de problemas mais precisos, no caso, a luz que o presente artigo lança é sobre os conflitos urbanos inerentes ao exercício do direito à cidade e a gentrificação, busca-se explorar potencialidades dos instrumentos para eclosão de conflitos revelados e camuflados da vida em sociedade destes espaços.

Em relação ao desenho metodológico do presente artigo, é válido recuperar o posicionamento de Gil (2008). O referido autor pontua que um conhecimento é científico, se possibilitar a identificação das operações mentais e técnicas para futura verificação e replicação dos procedimentos adotados (GIL, 2008, p.27). neste contexto, é e essencial, 
indicar a escolha do método científico adotado, que no caso o método dialético. Gil (2008, p.28), defini esse método como sendo aquele que "apresenta procedimentos lógicos que deverão ser seguidos no processo de investigação científica dos fatos da natureza e da sociedade". Justifica-se essa escolha pois, este trabalho guarda estreita relação com tais características, basta observar que o objeto é ato inerente à vida em sociedade.

Nota-se, ainda, que as pesquisa nas ciências sociais aplicadas, tal qual o caso do direito, podem ser classificadas especificamente, em produções cujos objetivos são: o descritivo, o explicativo e o exploratório (GIL, 2008). Neste caso, esta pesquisa apesentou objetivo exploratório, cuja característica principal é "desenvolver, esclarecer e modificar conceitos e ideias, tendo em vista a formulação de problemas mais precisos ou hipóteses pesquisáveis para estudos posteriores". (GIL, 2008, p.46). Em formato ilustrativo, esse é exatamente o objetivo desta pesquisa, evidenciar-se-á uma análise exploratório dos conflitos oriundos do exército à gentrificação frente às imposições do direito à cidade.

Em alinhamento ao método definido, efetivou-se também, o delineamento prático das atividades de pesquisa. Sendo assim, pondera-se que o delineamento "refere-se ao planejamento da pesquisa em sua dimensão mais ampla, envolvendo tanto a sua diagramação quanto a previsão de análise e interpretação dos dados” (GIL, 2008, p.68). Entre outros aspectos, o delineamento considera o ambiente em que são coletados os dados, no caso, foram coletados pela triangulação de dois procedimentos: a) revisão da literatura, as quais foram analisadas utilizando-se dos procedimentos da revisão integrativa; b) pesquisa documental, cujas fontes foram as legislações e normativas vigentes, tanto as produzidas em âmbito internacional (Declaração Universal de Direitos Humanos; Pacto Internacional dos Direitos Econômicos, Sociais e Culturais; Pacto Internacional de Direitos Civis e Políticos; Protocolo Adicional à Convenção Americana Sobre Direitos Humanos em Matéria de Direitos Econômicos, Sociais e Culturais - Protocolo de San Salvador) quantos as de efeito nacional (Constituição da República Federativa do Brasil; Estatuto da Cidade; Código Civil; e Lei de Regularização Fundiária Urbana), todas disponibilizados em plataformas digitais e de acesso livre. Tais documentos analisados a partir da técnica da análise de conteúdo.

\section{O DIREITO À CIDADE COMO DIREITO HUMANO FUNDAMENTAL}

A Constituição Federal prevê, em seu artigo $6^{\circ}$, como direito fundamental social, o direito à moradia ao lado de diversos outros direitos considerados como básicos para uma 
vida digna. Tais direitos sociais são classificados pela maioria da doutrina como direitos programáticos, ou seja, direitos garantidos pelo Estado de forma progressiva e de acordo com diversos fatores, como a capacidade econômica do Estado, a distribuição de bens, nível de ensino, desenvolvimento econômico, e até mesmo o clima espiritual da sociedade (CANOTILHO, 2003). Apesar disso, a Constituição brasileira expressamente prevê a aplicabilidade imediata de tais direitos, considerados pela maioria da doutrina como direitos humanos de segunda dimensão (ou geração), tendo em vista que se afastam daqueles direitos de liberdade habitualmente garantidos por instrumentos processuais constitucionais (MAZZUOLI, 2020).

Esta aplicabilidade imediata prevista constitucionalmente não obriga que o Estado garanta tais direitos sociais a todos os seus cidadãos de forma indiscriminada. Porém, tais direitos devem ser observados nas políticas públicas adotadas no âmbito da competência de cada ente federativo, bem como impede que normas legais ou infralegais violem com retrocessos tais disposições constitucionais (SILVA, 2008). Nesse mesmo sentido, o Protocolo Adicional à Convenção Americana Sobre Direitos Humanos em Matéria de Direitos Econômicos, Sociais e Culturais, conhecido como Protocolo de San Salvador, reconhece que o dever dos Estados signatários em garantir tais direitos deve estar ligado ao seu grau de desenvolvimento, ao mesmo tempo em que os obriga a dar plena efetividade aos comandos do referido tratado de forma progressiva e utilizando o máximo de recursos disponíveis (ORGANIZAÇÃO DOS ESTADOS AMERICANOS, 1988).

Ainda, esses mesmos direitos servem como vetores de garantia de diminuição da desigualdade social, de forma a impulsionar prestações positivas por parte do Estado que voltem os olhos àqueles em situação de vulnerabilidade.

Assim, podemos dizer que os direitos sociais, como dimensão dos direitos fundamentais do homem, são prestações positivas proporcionadas pelo Estado direta ou indiretamente, enunciadas em normas constitucionais, que possibilitam melhores condições de vida aos mais fracos, direitos que tendem a realizar a igualização de situações sociais desiguais. São, portanto, direitos que se ligam ao direito de igualdade. Valem como pressupostos do gozo dos direitos individuais na medida em que criam condições materiais mais propícias ao auferimento da igualdade real, o que, por sua vez, proporciona condição mais compatível com o exercício efetivo da liberdade (SILVA, 2008). 
Dessa forma, o direito à moradia previsto constitucionalmente deve servir de parâmetro para a adoção de políticas públicas a fim de diminuir a desigualdade social, objetivo da República Federativa do Brasil expressamente previsto no artigo $3^{\circ}$, inciso III, da Constituição Federal. Importante destacar que todos os entes federativos, União, Estados, Distrito Federal e Municípios possuem competência para promoverem programas de moradia e melhoria de condições habitacionais, conforme art. 23, inciso XI, da Constituição Federal. Essa imposição constitucional às três esferas de governo sobre o direito à moradia demonstra a importância que tal direito possui no ordenamento jurídico pátrio (CASTRO, 2001).

Partindo de tal pressuposto, é necessário que se estabeleça a verdadeira extensão do direito à moradia. Em um primeiro momento, pode-se entender que o direito à moradia é equivalente ao direito à habitação. Acontece que a noção de habitação é ligada à simples existência de um teto sobre a cabeça ou um lugar para dormir, o que não corresponde com a intenção do constituinte ao incluir a moradia no rol dos direitos sociais fundamentais.

O conteúdo do direito à moradia envolve não só a faculdade de ocupar uma habitação. Exige-se que seja uma habitação de dimensões adequadas, em condições de higiene e conforto e que preserve a intimidade pessoal e a privacidade familiar, como se prevê na Constituição portuguesa (art. 65). Em suma, que seja uma habitação digna e adequada, como quer a Constituição espanhola (art. 47). Nem se pense que estamos aqui reivindicando a aplicação dessas constituições ao nosso sistema. Não é isso. É que a compreensão do direito à moradia, como direito social, agora inserido expressamente em nossa Constituição, encontra normas e princípios que exigem que ele tenha aquelas dimensões. Se ela prevê, como um princípio fundamental, a dignidade da pessoa humana (art. $1^{\circ}$, III), assim como o direito à intimidade e à privacidade (art. $\left.5^{\circ}, \mathrm{X}\right)$, e que a casa é um asilo inviolável (art. $\left.5^{\circ}, \mathrm{XI}\right)$, então tudo isso envolve, necessariamente, o direito à moradia. Não fosse assim seria um direito empobrecido (SILVA, 2008).

Assim, o direito constitucional à moradia parte de um direito à moradia adequado, de forma que a habitação deve garantir uma vida com dignidade e segurança. Sem observar tal requisito, qual seja, a adequação da moradia, esse direito não pode ser considerado efetivado. É o que podemos verificar quando observamos moradias em lugares perigosos ou instaladas de forma precária, pessoas que moram em locais provisórios como abrigos e albergues, ou, ainda, moradias que não dispõem de serviços públicos essenciais como saneamento básico ou energia elétrica. 
Esse mesmo direito é previsto internacionalmente em alguns tratados internacionais de direitos humanos ratificados pelo Brasil. A Declaração Universal dos Direitos Humanos dispõe que todos têm direito ao bem-estar, incluindo habitação e serviços sociais indispensáveis (ORGANIZAÇÃO DAS NAÇÕES UNIDAS, 1948). O Pacto Internacional sobre Direitos Civis e Políticos prevê a inviolabilidade do domicílio em seu artigo 17 (ORGANIZAÇÃO DAS NAÇÕES UNIDAS, 1948). Já o Pacto Internacional sobre Direitos Econômicos, Sociais e Culturais ("PIDESC"), no artigo 11, reconhece com mais profundidade o direito à moradia. Indo além à própria previsão da moradia como direito, ao contrário da Constituição Federal, o PIDESC reconhece que a moradia deve ser adequada, estabelecendo que todos têm direito a um nível de vida adequada para si próprio e para sua família (ORGANIZAÇÃO DAS NAÇÕES UNIDAS, 1966). Gazola (2008) entende o direito à moradia adequada não só como um espaço físico estruturado, mas também com a noção de um espaço psicológico e humano de acolhimento.

O Comitê de Direitos Econômicos, Sociais e Culturais, ao interpretar o artigo 11 do PIDESC, ratifica a ideia de que o direito à moradia não se limita à existência de um lugar para habitação. Pelo contrário, o órgão da Organização das Nações Unidas afirma que tal direito não pode ser aplicado de forma restritiva, tampouco interpretado como sendo um simples teto sobre a cabeça do indivíduo. A moradia deve ser encarada como uma forma de garantir a vida, segurança, paz e dignidade da pessoa, estando intimamente ligada com a fruição de diversos outros direitos humanos. O Comitê continua sua análise passando a elencar quais os aspectos devem ser considerados para que a moradia possa se tornar adequada, chegando à conclusão de que os seguintes requisitos devem ser observados: (i) segurança legal da posse; (ii) disponibilidade de serviços, materiais, facilidades e infraestrutura; (iii) custo acessível; (iv) habitabilidade; (v) acessibilidade; (vi) localização; e (vii) adequação cultural (ORGANIZAÇÃO DAS NAÇÕES UNIDAS, 1991).

Dos critérios analisados pelo Comitê instituído pelo PIDESC para a garantia direito à moradia adequada, no contexto urbano, destaca-se a localização como um dos elementos listados. Isso porque não basta a estrutura da própria moradia para que se afirme que o direito está garantido. É necessário que a localização disponibilize o acesso a opções de trabalho, serviços de saúde, creches, escolas e demais serviços públicos (ORGANIZAÇÃO DAS NAÇÕES UNIDADES, 1991). 
A partir dessa definição de direito à moradia, é preciso verificar a aplicabilidade de tal direito dentro de grandes centros urbanos e, em que profundidade este garante o acesso à urbe no Brasil. No início do século XX, em decorrência da industrialização, os locais urbanos foram o foco da população, principalmente da classe trabalhadora que buscava oportunidades de emprego. A rápida migração de pessoas para os grandes centros urbanos tornou impossível que se impedisse o crescimento desordenado da cidade, sendo as políticas públicas habitacionais da época pouco eficientes para garantir o acesso à moradia adequada e regularizada (HOLZ; MONTEIRO, 2008). Este crescimento desenfreado e a constante luta por espaços urbanos evidencia a desigualdade social na cidade levando a um processo de segregação em desfavor da população de baixa renda e, ao mesmo tempo, uma elevação da concentração de riquezas em favor daqueles economicamente mais favorecidos (COSTA, 2014).

É na cidade, contudo, que é possível analisar com clareza a pluralidade de classes, ideias e interesses que, frequentemente, se chocam e geram conflitos. Essa troca de experiências é tratada por Lefebvre (2001) como um aspecto natural da democracia, de forma que a urbe, como centro de relações sociais e políticas, intensifica o próprio regime democrático e, por essa razão, deve ser usufruída por todos, independentemente de classe social. Entretanto, na prática, em decorrência dos mesmos aspectos históricos que fizeram surgir o crescimento urbano de forma não ordenada no Brasil, as cidades passaram de um ideal democrático a verdadeiros núcleos estruturais antidemocráticos, na medida em que aqueles que menos dispõem são jogados à periferia ou segregados das oportunidades que a própria cidade oferece (COSTA, 2014).

É neste contexto de conflitos e exclusão social que se começa a desenvolver o direito à cidade como intrínseco ao direito à moradia, mas, ao mesmo tempo, mais amplo do que aquele. $\mathrm{O}$ direito à cidade é compreendido não somente como o direito a viver em um centro urbano, mas como o direito à participação democrática nesse mesmo local de habitação, com usufruto dos serviços e facilidades que lhe são propiciados. Conforme Lefebvre (2001):

$\mathrm{O}$ direito à cidade não pode ser concebido como um simples direito de visita ou de retorno às cidades tradicionais. Só pode ser formulado como direito à vida urbana, transformada, renovada. Pouco importa que o tecido urbano encerre em si o campo e aquilo que sobrevive da vida camponesa conquanto que "o urbano", lugar de encontro, prioridade do valor de uso, inscrição no espaço de um tempo promovido à posição de supremo bem entre os bens, 
encontre sua base morfológica, sua realização prático-sensível. O que pressupõe uma teoria integral da cidade e da sociedade urbana que utilize os recursos da ciência e da arte. Só a classe operária pode se tornar o agente, o portador ou o suporte social dessa realização. Aqui ainda, como há um século, ela nega e contesta, unicamente com sua presença, a estratégia de classe dirigida contra ela. Como há um século, ainda que em novas condições, ela reúne os interesses (aqueles que superam o imediato e o superficial) de toda a sociedade, e inicialmente de todos aqueles que habitam. Os moradores do Olimpo e a nova aristocracia burguesa (quem o ignora?) não habitam mais. [grifos do autor]

Portanto, o direito à cidade surge como direito social e, ao mesmo tempo, como direito coletivo das classes economicamente inferiores, servindo como instrumento de resistência e participação democrática. Por essa razão, a cidade passa a ser observada e estudada não apenas como um local de moradia, mas como um espaço de exercício de diversos outros direitos. Paradoxalmente, esse mesmo espaço evidencia a desigualdade social e joga luz à ausência de garantia de direitos para esses grupos vulnerabilizados. A solução seria, então, o reconhecimento do direito à cidade, com sua consequente democratização, a fim de que o processo de urbanização e transformação de espaços considerem os diferentes níveis de posição social e as diferentes reivindicações dos grupos existentes nos centros urbanos (HARVEY, 2017).

No ordenamento jurídico brasileiro, a Lei n ${ }^{\circ} 10.257 / 2001$, conhecida como o Estatuto da Cidade, trouxe diversos instrumentos capazes de efetivar o direito à permanência em centros urbanos. A mesma lei elenca como diretriz o direito à cidade sustentável, compreendida como o direito à terra urbana, à moradia, ao saneamento ambiental, ao transporte e aos serviços públicos, ao trabalho e ao lazer. Da mesma forma, garante o direito à gestão democrática por meio da participação da população e de associações representativas de diversos segmentos da comunidade. Em seu artigo $1^{\circ}$, o Estatuto da Cidade regula o uso da propriedade urbana em prol do bem coletivo, da segurança e bem-estar dos cidadãos. Percebese, assim, que a legislação que regulamenta os espaços urbanos no Brasil vai ao encontro do direito à cidade da forma como pensado por Lefebvre, bem como se aproxima daqueles requisitos dispostos pelo Comitê da ONU instituído no PIDESC. A própria Constituição Federal, ao prever um capítulo específico sobre a política urbana brasileira, trazendo mecanismos de controle do abuso da propriedade urbana, acaba por endossar a existência de um direito à cidade, apesar de não o fazer expressamente. 
Ou seja, a lei incorporou o direito à cidade de forma expressa, trazendo ao ordenamento jurídico brasileiro uma concepção mais ampla do que o direito à moradia, com o nítido objetivo de garantir a democratização do espaço urbano principalmente em favor dos mais pobres.

\section{OS CONFLITOS NOS GRANDES CENTROS URBANOS E O FENÔMENO DA GENTRIFICAÇÃO}

A gentrificação é um fenômeno social observado em grandes centros urbanos e que consiste na expulsão silenciosa e não ordenada de habitantes de classes sociais baixas de regiões mais desenvolvidas para, geralmente, regiões periféricas. A gentrificação ocorre, em geral, quando há melhorias estruturais em determinada região da cidade, trazendo, como consequência, um aumento no valor das habitações e no preço médio de vida dos habitantes. As melhorias que causam a gentrificação costumam ocorrer em centros urbanos históricos, com a ocupação dessas regiões pela classe média ou alta, deslocando aqueles de classe baixa que antes ali viviam. Os investimentos para a elevação do status social não ocorre somente nas propriedades do centro urbana, mas também em toda a área afetada pelo fenômeno, incluindo o comércio, serviços públicos, equipamentos sociais etc. (BATALLER, 2000).

O termo gentrificação é atribuído a Glass e vem da expressão "gentry" utilizada para se referir à classe média-alta inglesa das áreas rurais, já que possuíam residência tanto no campo, quanto na cidade. Apesar de ser o termo mais utilizado, além da gentrificação, outras expressões são usadas para definir o mesmo fenômeno, tais como "brownstoning", “whitepainting” ou aristocratização (BATALLER, 2000). Apesar de ser um acontecimento tipicamente urbano, a gentrificação não é atual. Smith (1986) demonstra que no século XIX já existia uma tendência de reestruturação da cidade, com centros dominados pelos profissionais executivos com funções financeiras e administrativas e construções de casas de classes média e alta. O mesmo autor observa que, juntamente com tal transformação, os serviços públicos típicos dessas classes também foram trazidos aos centros, tais como restaurantes, hotéis, cinemas e opções culturais. Com isso, houve um desalojamento da classe trabalhadora, empurrada para os subúrbios e periferias. Em 1872, Engels já estabelecia uma relação entre a questão da habitação e a industrialização, relatando as condições precárias de vida dos trabalhadores (GOMES, 2005). 
Apesar da existência de um padrão de deslocamento forçado da classe baixa para regiões periféricas em razão do aumento de melhorias e custo de vida nas regiões centrais, a gentrificação ocorre de forma diferente ao redor do mundo, variando de acordo com o centro urbano estudado (FURTADO, 2014). No Brasil, o processo de gentrificação remonta à abolição da escravatura e a industrialização em massa que atraem os antigos trabalhadores da lavoura para os centros urbanos. Com o êxodo de trabalhadores, o cortiço passa a ser a opção mais rentável para os novos habitantes do centro, bem como aos próprios proprietários que especulavam a única opção de moradia por grande parte da população. Nesse mesmo momento, ganha espaço uma política urbana da então capital do Brasil, o Rio de Janeiro, que possuía o escopo de intervenção estatal para a renovação e higienização da cidade. Tal movimento trouxe uma falsa justificativa sanitária para colocar fim aos cortiços e, consequentemente, expulsar seus moradores. Durante a Ditadura Militar, foi mantida uma fracassada política de remoção compulsória, porém, voltada principalmente à erradicação das favelas do Rio de Janeiro (GOMES, 2005).

Atualmente, contudo, as características da cidade impedem que a gentrificação seja identificada com clareza. Se, por um lado, sabemos que existe especulação imobiliária e que as políticas de habitação em centros urbanos são evidentemente insuficientes para atender a população mais pobre, por outro, as classes sociais urbanas não são tão bem distinguíveis. A desorganização da urbe acaba criando uma falsa percepção de homogeneidade de seus habitantes, quando, na verdade, as práticas sociais e modos de vida são heterogêneos. Assim, o processo de gentrificação moderno se encontra em um contexto de mudança social e econômica, criando uma verdadeira nova classe média em distinção àquele conceito tradicional (MENDES, 2011).

Esse processo, apesar de identificável, é complexo e envolve não somente a pressão para remoção da população indesejada do espaço urbano, como também interesses econômicos e delimitação territorial cada vez mais nítidas entre classes sociais diferentes.

Hoje, o vínculo entre o desenvolvimento econômico e geográfico persiste, conferindo à imagem de fronteira sua atualidade, mas a forma deste vínculo é bem diferente. No que diz respeito à base espacial, a expansão econômica ocorre hoje não por meio da expansão geográfica absoluta, mas pela diferenciação interna do espaço geográfico. A produção atual do espaço ou do desenvolvimento geográfico é, portanto, um processo acentuadamente desigual. A gentrificação, a renovação urbana e o mais amplo e complexo processo de reestruturação urbana são todos parte da diferenciação do espaço 
geográfico na escala urbana; e, embora estes processos tenham sua origem em um período anterior à atual crise econômica mundial, sua função hoje é reservar uma pequena parte do substrato geográfico para um futuro período de expansão. E assim como no caso da fronteira original, a mitologia afirma ser a gentrificação um processo liderado por pioneiros e proprietários individuais cujo suor, ousadia e visão estão preparando o caminho para aqueles, entre nós, que são mais temerosos. Mas mesmo que ignoremos a renovação urbana e o redesenvolvimento comercial, administrativo e recreacional que vem ocorrendo, e concentremos-nos apenas na reabilitação residencial, é patente o fato de que, onde quer que os "pioneiros urbanos" se aventurem, os bancos, as incorporadoras, o Estado e outros atores econômicos coletivos geralmente chegam antes (SMITH, 2007).

Portanto, o processo de gentrificação não acontece necessariamente de forma natural, sendo impulsionado por interesses econômicos e, muitas vezes, defendido e incentivado pelo próprio Estado. Acontece que a gentrificação acaba por violar direitos humanos básicos. Como vimos, o direito à cidade deve servir como parâmetro para as políticas habitacionais urbanas, já que previso no ordenamento jurídico brasileiro e sustentado tanto pela Constituição Federal, quanto por tratados internacionais de direitos humanos. A moradia adequada nos centros urbanos pressupõe o acesso a serviços públicos básicos e a segurança jurídica da posse. Apesar disso, a gentrificação faz com que, naturalmente, o direito à cidade seja ignorado tanto pelo Poder Público, quanto por agentes privados interessados na especulação imobiliária.

$\mathrm{Na}$ medida em que a gentrificação afasta a população mais pobre do acesso democrático à cidade, não se pode falar que direitos humanos são respeitados. Esse modelo excludente de segregação geográfica no Brasil não é suprido pelas políticas públicas habitacionais existentes (COUTINHO et. al., 2014). A maioria dos programas de moradia incentivados pelo Poder Público afasta os moradores do centro urbano e apresenta limitações que, por vezes, não são atrativas aos trabalhadores do centro da cidade, além de pouco oferecer quanto a estruturas físicas adequadas. Não raro, conjuntos habitacionais causam, inclusive, desconforto ambiental, falta de autoestima e sentimento de não pertencimento, podendo gerar conflitos no seio da comunidade (LAY; REIS, 2002).

Assim, em face de uma violação de direito, cabe saber quais instrumentos jurídicos são capazes de corrigir e impedir a gentrificação e esses mesmos instrumentos são suficientes para que o problema seja tratado e, eventualmente, resolvido. 


\section{INSTRUMENTOS JURÍDICOS DE LIMITAÇÃO À GENTRIFICAÇÃO PARA A RESOLUÇÃO ADEQUADA DOS CONFLITOS URBANOS GERADOS}

Sendo a gentrificação fenômeno social violador do direito à cidade, cabe ao Direito a tarefa de estabelecer instrumentos jurídicos capazes de tutelar, na medida do possível, o bem jurídico protegido pela norma. Nesse aspecto, a proteção do direito à cidade passa pela necessária garantia de segurança jurídica da posse, nos termos propostos pelo Comitê de Direitos Econômicos, Sociais e Culturais da ONU, onde o Estado deve garantir a todos, certo grau de segurança da posse, com a devida proteção legal contra despejos forçados e outras ameaças, independentemente da ausência de propriedade sobre o bem e do tipo de posse exercida (ORGANIZAÇÃO DAS NAÇÕES, 1991).

A Constituição Federal elenca a propriedade como direito fundamental. Historicamente, a propriedade privada já detinha caráter de direito humano, cabendo ao Estado garantir sua proteção (COMPARATO, 2000). Contudo, no inciso seguinte, a CF vincula o exercício da propriedade à sua função social, repetindo esse mesmo princípio em seu artigo 170, inciso III, quando trata da ordem econômica e financeira. O Código Civil também preconiza o princípio quando impõe que o direito de propriedade seja exercido de acordo com as finalidades econômicas e sociais, privilegiando o coletivo em detrimento do individual.

Nesse sentido, o princípio da função social da propriedade impõe um verdadeiro dever (função social) ao titular de um direito fundamental (direito de propriedade), sendo comando imperativo, de eficácia plena e de ordem pública, originado do próprio texto constitucional (DIDIER JÚNIOR, 2008). O princípio obriga que o titular do domínio justifique o exercício devido de seu direito, compatibilizando a ideia de propriedade típica de um sistema capitalista com a democracia social sustentada pela Constituição Federal (SCHREIBER, 2001).

A partir desse pressuposto, é necessário que os instrumentos que garantem o direito à cidade frente à gentrificação sejam analisados de acordo com o princípio constitucional da função social da propriedade. Assim, passamos à análise dos meios jurídicos que possam, eventualmente, permitir a permanência de um habitante no centro urbano da cidade, em resistência ao processo de gentrificação.

O Código Civil tenta estabelecer proteção à posse através de dispositivos que limitam o exercício da própria propriedade em favor daquele que exerce a posse. Um dos 
instrumentos mais conhecidos é a usucapião, modalidade de aquisição da propriedade de bens móveis ou imóveis pelo exercício da posse pacífica pelo período fixado em lei. O prazo varia de acordo com diversos fatores, tais como: a existência de justo título; a existência de boa-fé; a realização de obras que valorizem a propriedade; a utilização da propriedade para fins familiares; entre outros (SCHAEFER, 2004). Porém, é a própria Constituição que define uma espécie específica de usucapião capaz de se concretizar tão somente em áreas urbanas. A usucapião especial urbana é prevista no artigo 183 da Constituição Federal e replicada tanto no Código Civil, quanto no Estatuto da Cidade. Essa modalidade em especial exige que a área objeto da usucapião não ultrapasse duzentos e cinquenta metros quadrados, que interessado a possua por ao menos cinco anos e que o imóvel seja utilizado para moradia própria ou de sua família. Existe, ainda, um requisito negativo, sendo que o requerente não pode possuir outro imóvel.

Acontece que, apesar de ser importante instrumento individual de aquisição da propriedade urbana, garantindo segurança jurídica contra tentativas de reintegração, é certo que a usucapião não atende os anseios da população que sofre com a gentrificação, uma vez que esta atinge comunidades inteiras de maneira, muitas vezes, não explícita.

Assim, instrumentos coletivos de proteção da posse e propriedade são mais eficazes na democratização do espaço urbano. O Estatuto da Cidade, atento a esta realidade de necessidade de garantia de segurança coletiva da posse, por bem, criou modalidade de usucapião, conhecida como especial urbana coletiva. A lei, então, trouxe praticamente os mesmos requisitos da usucapião constitucional aos núcleos urbanos informais, garantindo a propriedade de forma coletiva. Com a consolidação da propriedade em nome da comunidade, torna-se possível a melhoria da área de acordo com os interesses dos próprios moradores, dispondo o grupo de maior estabilidade e proteção jurídica contra pressões econômicas externas.

Por outro lado, os requisitos para a declaração de usucapião não são atendidos por todos os grupos que têm seu direito à cidade ameaçado. Assim, a lei cria outro instrumento capaz de atender ao menos parte da população urbana que precisa ter segurança jurídica de sua posse. Trata-se da regularização fundiária urbana através de dois instrumentos próprios previstos na Lei ${ }^{\circ}$ 13.446/2017: a legitimação fundiária e a legitimação de posse. Quanto à legitimação fundiária, esta é considerada pela lei como direito real de propriedade conferido por ato do Poder Público a quem possui área privada ou detém área pública com destinação 
urbana em núcleos informais consolidados até o dia 22 de dezembro de 2016. Já a legitimação de posse garante o reconhecimento por parte do Poder Público da posse exercida em determinada área urbana, com identificação de seus ocupantes, a natureza da posse e o tempo de ocupação, convertendo-se, posteriormente, em direito real de propriedade.

Judicialmente, também é possível o reconhecimento de propriedade de uma coletividade através de do que a doutrina chama de desapropriação judicial. O Código Civil afirma que o proprietário pode ser privado do domínio da coisa se o imóvel constituir em extensa área, na posse ininterrupta e de boa-fé de elevado número de pessoas por mais de cinco anos e se essas mesmas pessoas realizaram obras e serviços de interesse social e econômico relevante. Essa desapropriação imposta pelo Poder Judiciário está relacionada à concretização do direito humano à cidade e deve ser encarada como verdadeira política pública estabelecida pelo legislador ordinário (CARNEIRO, 2008).

Importante destacar que vários destes instrumentos não dependem da intervenção judicial para que possam solucionar o conflito urbano eventualmente gerado com a gentrificação. Muito pelo contrário, é possível verificar que a maioria dos procedimentos previstos em lei podem ser utilizados pela parte interessada extrajudicialmente. Podemos destacar a possibilidade de usucapião extrajudicial, conforme a alteração trazida pela Lei $\mathrm{n}^{\circ}$ 13.105 de 2015 (Código de Processo Civil) na Lei nº 6.015 de 1973 (Lei de Registros Públicos). Ainda, não é demais lembrar que tanto a legitimação fundiária quanto a legitimação de posse são procedimentos de reconhecimento do Poder Público que não precisam do crivo do Judiciário, bastando, tão somente, o reconhecimento do ente federativo competente. Tais possibilidades geram importante avanço no reconhecimento da titularidade de imóveis sem a necessidade de judicialização da causa, evitando conflitos previamente e possibilitando uma resolução mais célere e eficaz do problema.

Portanto, em que pese a dificuldade na identificação e limitação à gentrificação, é certo que o próprio Direito deve servir como limite ao fenômeno urbano, tendo em vista a existência de instrumentos próprios capazes de, ao menos, estabelecer maior segurança jurídica às comunidades que ocupam espaços urbanos informais. Mais do que garantir a moradia adequada, esses institutos jurídicos visam a imposição do direito à cidade contra tentativas de expulsão de classes mais baixas a regiões periféricas da cidade.

\section{CONSIDERAÇÕES FINAIS}


$\mathrm{O}$ ordenamento jurídico brasileiro prevê o direito à cidade. Em que pese a inexistência de previsão expressa na Constituição Federal, interpretações de órgãos internacionais de proteção sobre o direito à moradia adequada demonstram que o direito à cidade tem características típicas de direitos humanos. Soma-se a isto o fato de que a Constituição Federal prevê capítulo específico que regulamenta a ordem urbana brasileira e suas políticas públicas, garantindo a função social da propriedade como princípio de observância obrigatória por parte do Poder Público.

$\mathrm{O}$ direito à cidade nesse contexto se mostra muito maior do que o direito à moradia, na medida em que não se esgota na garantia de um teto sobre a cabeça do cidadão. Para que o direito à cidade seja garantido, é preciso que a moradia abranja condições dignas de vida e acesso a serviços públicos básicos. De acordo com essa perspectiva, o espaço urbano se é tido como um organismo vivo composto por diversas classes sociais e representa um núcleo representativo da própria democracia.

Contudo, de maneira contraditória, a cidade acaba por revelar seu lado segregador e excludente, evidenciando a intensa desigualdade social sofrida por seus habitantes e, consequentemente, trazendo conflitos entre os cidadãos. Um dos fenômenos que ratifica esse lado antidemocrático da urbe é o processo de gentrificação, caracterizado como uma pressão social e econômica contra pessoas de baixa renda nos grandes centros urbanos. Com a melhoria de serviços públicos centrais, aumento do status social familiar e elevação do custo de vida na cidade, trabalhadores tendem a deixar estes espaços com acesso mais facilitado a serviços públicos para se fixar em regiões periféricas. Não se conclui, contudo, que a gentrificação é natural. Grandes interesses econômicos acabam por conscientemente impulsionar a gentrificação, de forma a tomar espaços economicamente vantajosos nos centros urbanos, criando, com isso, novos conflitos.

Uma das formas de se garantir o direito à cidade é justamente dar segurança jurídica à posse ou à propriedade, de forma que pressões externas não possuam tanta força contra os menos favorecidos. O sistema jurídico, assim, se torna fundamental para disponibilizar instrumentos capazes de fazer valer o direito à cidade. Dessa forma, a legislação prevê institutos que garantem o reconhecimento do direito de permanência de forma coletiva, tais como: a usucapião especial urbana coletiva; a legitimação fundiária e a legitimação de posse, no âmbito da regularização fundiária urbana; e a desapropriação judicial. Parte destes instrumentos legalmente previstos sequer demandam intervenção do Poder Judiciário, 
podendo a posse ou a propriedade, a depender do caso, ser reconhecida de maneira extrajudicial, evitando a judicialização e trazendo segurança jurídica à parte interessada.

Esses instrumentos certamente não são suficientes para garantir uma pacificação social completa na cidade. Aliás, a própria característica democrática do espaço urbano pressupõe conflitos entre classes diferentes. Porém, nesse aspecto de constantes tentativas de exclusão social, o Direito, mesmo que de maneira extrajudicial, serve como limite mínimo à gentrificação, garantindo, ao menos, mansidão quanto à posse ou propriedade de áreas urbanas em certos casos.

\section{REFERÊNCIAS}

BATALlER, M. A. S. O Estudo da Gentrificação. Trad. Maurilio Lima Botelho. Revista Bibliográfica de Geografía y Ciencias Sociales, n. 228. Universidad de Barcelona. Barcelona, 2000.

BRASIL. Constituição da República Federativa do Brasil. 1988.

BRASIL. Lei $n^{o}$ 10.257, de 10 de julho de 2001. Regulamenta os arts. 182 e 183 da Constituição Federal, estabelece diretrizes gerais da política urbana e dá outras providências. 2001.

BRASIL. Lei $n^{o}$ 10.406, de 10 de janeiro de 2002. Institui o Código Civil. 2002.

BRASIL. Lei $n^{\circ} 13.465$, de 11 de julho de 2017. Dispõe sobre a regularização fundiária rural e urbana, sobre a liquidação de créditos concedidos aos assentados da reforma agrária e sobre a regularização fundiária no âmbito da Amazônia Legal; institui mecanismos para aprimorar a eficiência dos procedimentos de alienação de imóveis da União. 2017.

CANOTILHO, J. J. G. Direito Constitucional e Teoria da Constituição. $7^{\mathrm{a}}$ edição. Coimbra: Almedina, 2003.

CARNEIRO, W. A. O Novo Código Civil e as Políticas Públicas: Uma análise da desapropriação judicial. Direito UNIFACS - Debate Virtual, v. 102, n. 102, 2008.

CASTRO, S. R. Habitação: direito e governança. Revista de Administração Pública, vol. 35, p. 111-126. Rio de Janeiro, 2001.

COMPARATO, F. K. Direitos e deveres fundamentais em matéria de propriedade. In.:

STROZAKE, J. J. (Org.). A questão agrária e a justiça. São Paulo: Revista dos Tribunais, 2000. 
COSTA, S. S. Impactos da política de habitação social e o direito humano à moradia no Brasil. Revista Interdisciplinar de Direitos Humanos, vol. 2, n. 3, p. 191-206. Universidade Estadual Paulista Júlio de Mesquita Filho - UNESP. Bauru, 2014.

COUTINHO, D.R.; MARQUES, J. N.; MORETTI, J. A.; PACHECO, M. G.; ROZO, F. G. $O$ Direito nas Políticas Públicas Urbanas e Habitacionais: O Uso de Instrumentos Urbanísticos no Município de Santo André, São Paulo. Cadernos Gestão Pública e Cidadania, v. 19, n. 64. São Paulo, 2014.

DIDIER JÚNIOR, F. A função social da propriedade e a tutela processual da posse. Revista de Processo. Instituto Brasileiro de Direito Processual (IBDP). São Paulo: Revista dos Tribunais, 2008.

FURTADO, C. R. Intervenção do Estado e (re)estruturação urbana: Um estudo sobre gentrificação. Cadernos Metrópole, vol. 16, n. 32, p. 341-363. Pontifícia Universidade Católica de São Paulo. São Paulo, 2014.

GAZOLA, P. M. Concretização do direito à moradia digna: teoria e prática. Belo Horizonte: Fórum, 2008.

GOMES, M. F. C. M. Habitação e Questão Social - Análise do Caso Brasileiro. Revista Eletrónica de Geografía y Ciencias Sociales. Universidad de Barcelona, vol. IX, n. 194. Barcelona, 2005.

HARVEY, D. O Direito à Cidade. Trad. Jair Pinheiro. Lutas Sociais, n. 29, p. 73-89. São Paulo, 2019.

HOLZ, S.; MONTEIRO, T. V. A. Política de Habitação Social e o Direito a Moradia no Brasil. X Coloquio Internacional de Geocrítica. Universidad de Barcelona. Barcelona, 2008. LAY, M. C. D.; REIS, A. T. L. O papel de espaços abertos comunais na avaliação de desempenho de conjuntos habitacionais. Ambiente Construído, v. 2, n. 3, p. 25-39. Porto Alegre, 2002.

LEFEBVRE, H. O direito à cidade. São Paulo: Centauro, 2001.

MAZZUOLI, V. O. Curso de Direitos Humanos. $7^{\mathrm{a}}$ edição. São Paulo: Método, 2020.

MENDES, Luís. Cidade pós-moderna, gentrificação e a produção social do espaço fragmentado. Cadernos Metrópole, v. 13, n. 26, p. 473-495. Pontifícia Universidade Católica de São Paulo. São Paulo, 2011.

ORGANIZAÇÃO DAS NAÇÕES UNIDAS. Comitê sobre os Direitos Econômicos, Sociais e Culturais. Comentário Geral no 4. UN doc E/1992/23. 1991. 
ORGANIZAÇÃO DAS NAÇÕES UNIDAS. Declaração Universal de Direitos Humanos. Adotada e proclamada pela Resolução nº 217 A (III) da Assembleia Geral das Nações Unidas, 1948.

ORGANIZAÇÃO DAS NAÇÕES UNIDAS. Pacto Internacional dos Direitos Econômicos, Sociais e Culturais. Adotado pela Resolução n. 2.200-A (XXI) da Assembleia-Geral das Nações Unidas. 1966.

ORGANIZAÇÃO DAS NAÇÕES UNIDAS. Pacto Internacional sobre Direitos Civis e Políticos. Adotado pela Resolução n. 2.200-A (XXI) da Assembleia-Geral das Nações Unidas. 1966.

ORGANIZAÇÃO DOS ESTADOS AMERICANOS. Protocolo Adicional à Convenção Americana Sobre Direitos Humanos em Matéria de Direitos Econômicos, Sociais e Culturais (Protocolo de San Salvador). Adotado durante à XVIII Assembleia-Geral da Organização dos Estados Americanos. San Salvador, 1988.

SCHAEFER, J. J. R. Usucapião: Conceito, Requisitos e Espécies. Revista da Jurisprudência Catarinense, vol. 30, n. 104-105. Santa Catarina, 2004.

SCHREIBER, A. Função social da propriedade na prática jurisprudencial brasileira. Revista Trimestral de Direito Civil, n. 6, 2001.

SILVA, J. A. Curso de Direito Constitucional Positivo. 30a edição. São Paulo: Malheiros, 2008.

SMITH, N. Gentrificação, a Fronteira e a Reestruturação do Espaço Urbano. Trad. Daniel de Mello Sanfelici. GEOUSP - Espaço e Tempo, n. 21, p. 15-31. São Paulo, 2007.

SMITH, N. Gentrification, the frontier, and the restructuring of urban space. In.: SMITH, N.; WILLIANS, P. (Orgs.). Gentrification of the city. Londres, 1986. 